\title{
IMPORTÂNCIA DA INTEGRAÇÃO DOCENTE-ASSISTENCIAL UMA TENTATIVA REALIZADA EM UM HOSPITAL MILITAR
}

\author{
Lêda Santos Pires* \\ Nilze Rodrigues Sobreira ** \\ Elza Ferreira de Candrina ***
}

ReBEn/09

PIRES, L.S. e Colaboradoras - Importância da Integração Docente-Assistencial - Ums Tentativa Realizada em um Hospital Militar — Rev. Bras. Enf.; DF, 35 : 95-101, 1982.

\section{RESUMO}

As autoras tecem consideraçōes sobre a integração Docente-Assistencial, como uma das estratégias utilizadas pelo Sistema Nacional de Saúde, na busca de melhores niveis de saúde da comunidade, visando a evitar a desarticulação existente entre o Ensino e a Realidade Prática, posicionando o problema como uma das preocupaçōes do corpo docente de um Curso de Graduação em Enfermagem de uma universidade particular.

Descrevem, outrossim, uma tentativa de integração Docente-Assisten-cial que se está realizando em caráter experimental, em um hospital militar e o departamento de enfermagem desta universidade.
Enfatizam os aspectos fundamentais dessa integração, suas bases conceituais, atividades desenvolvidas, objetivos que norteiam a integração, em consonância com o Sistema Nacional de Saúde e a política administrativa das instituições Formadora e Assistencial.

\section{INTRODUÇÃO}

Tem-se observado que, apesar das sucessivas buscas para a obtenção de melhores niveis de saúde do indivíduo, familia e comunidade, os indicadores persistem em evidenciar que os propósitos e metas do Sistema Nacional de Saúde estão ainda distantes de serem alcançados.

* Diretoria do Departamento de Enfermagem da Universidade Gama Filho - Doutora e Docente Livre pela Universidade do Estado do Rio de Janeiro (UNI-RIO) - Adjunta da Divisão de Ensino e Pesquisa do Hospital da Força Aérea do Galeão.

$\because: \%$ Professora do Departamento de Enferniagem da Universidade Gama Filho - Doutor e Docente Livre pela Universidade Federal do Rio de Janeiro (UFRJ) - Chefe do Serviço de Controle e Avaliação do Ensino do Departamento de Recusos Humanos da Secretaria de Estado de Saúde do Rio de Janeiro.

*: Enfermeira Chefe do Hospital de Força Aérea do Galeão - Rio de Janeiro. 
PIRES, L.S. e Colaboradoras - Importância da Integraçāo Docente-Assistencial - Uma Tentativa Realizada em um Hospital Militar - Rev. Bras. Enf.; DF, 35 : 95-101, 1982.

Tal afirmativa pode ser ratificada pela prevalência de algumas características dominantes no quadro assistencial, destacando-se:

- predominância de morbi-mortalidade, especialmente por doenças evitáveis;

- desequilíbrio entre demanda e oferta de assistência;

- necessidade de extensão de cobertura, prioritariamente da população carente e sub-atendida das zonas urbana e rural;

- aumento crescente das necessidades sentidas pela comunidade;

- atendimento inadequado dos clientes, redundando em recidivas de casos reinternações e aumento da demanda;

- discrepância conceitual e técnica entre os órgãos formadores e assistenciais; e

- reconhecimento da influência dos condicionamentos internos e externos na formação, na figuração da prática, definição de tendência e papéis profissionais.

Em face a esta problemática, o Governo vem utilizando várias estratégias conciliadoras, renovadoras ou remodeladoras da assistência, centradas precipuamente no processo de integração docente-assistencial e das Instituições de Saúde com o Sistema Tradicional de Saúde.

Selecionou-se a integração DocenteAssistencial para este estudo, devido à desarticulação ainda existente conforme ressalta a V Conferência Nacional de Saúde, bem como por estar intimamente relacionada com as atividades $e$ objetivos pretendidos no ensino-aprendizagem do Departamento de Enfermagem da Universidade Gama Filho, onde os alunos e professores precisam transpor-se das salas de aula para o campo da prática assistencial.
Outro motivo que deu ensejo à opção por este tema foi o fato de não se poder propiciar saúde para todos, sem o preparo da mão-de-obra, que envolve a assistência

\section{CARACTERIZAÇÃO DAS INSTITUI- ÇÕES ENVOLVIDAS}

Duas são as instituições envolvidas nesta tentativa de integração, selecionadas por apresentarem algumas peculiaridades:

a - Instituição de Ensino, configurada por:

- ser um órgão particular, com autonomia financeira;

- estar situada em uma região suburbana, implicando, portanto, em maior deslocamento do aluno e professor;

- gozar de alto prestígio social na área e na Cidade do Rio de Janeiro; e

- contar com um grande contingente de alunos cursando a graduação em enfermagem e obstetrícia.

b - Instituição Assistencial, caracterizando-se por:

- ser um órgão federal, de caráter privado e militar;

- possuir diversas clínicas para atendimento da clientela;

- estar localizada num bairro que dista da Universidade;

- haver em sua estrutura funcional elementos da equipe multiprofissional de saúde (civis e milatares), contando inclusive com enfermeiros:

- ser um hospital de linhas arquitetônicas arrojadas, recém-inaugurado e .equipado .com aparelhagem ultramoderna. 
PIRES, L.S. e Colaboradoras - Importância da Integraçāo Docente-Assistencial - Uma Tentativa Realizada em um Hospital Militar — Rev. Bras. Enf.; DF, 35 : 95-101, 1982.

\section{BASES CONCEITUAIS DA INTE- GRAÇÃO}

A integração empreendida, tem como bases conceituais:

\subsection{A SAÚDE PARA TODOS}

Interpretada pela premência de estenderem-se os programas de saúde a toda população, qualquer que seja o problema ou disponibilidade.

Fundamenta-se nos Direitos Humanos estabelecidos pela Organização das Naçōes Unidas (ONU), que enfatiza a saúde como um dos direitos humanos inalienáveis e, ainda, no homem como um ser psicossomático indivisível.

\subsection{OBJETIVOS QUE NORTEIAM A INTEGRAÇÃO}

Podem ser descritos, como: o dever e a oportunidade de:

- participar do Sistema Nacional de Saúde, que preconiza a necessidade de integração DocenteAssistencial;

- oferecer um ensino teórico-prático condizente com a realidade;

- participar ativamente no processo assistencial, agindo com a equipe multiprofissional, paciente e estrutura administrativa;

- possibilitar a formação ou moldagem de atitudes do aluno, desenvolvendo habilidades técnicas, o crescimento do potencial e promovendo a competência intelectual;

- permitir a maximização de efeitos positivos na prestação de serviços à clientela.

\subsection{ABRANGENCIA DO ENSINO}

O ensino e a integração programados, abrangem os seguintes aspectos:
- preparo;

- habilidades;

- identificação e solução de situações-problema e fatores impeditivos às ações;

- aplicacão de princípios técnicocientíficos;

- poder decisório;

- intervenção;

- desenvolvimento intelectual e do potencial do aluno.

\subsection{ABRANGÊNCIA DA ASSISTENNCIA}

A assistência oferecida pelos alunos através da prática envolve:

- os três níveis de prevençāo (primária, secundária e terciária), descritos por Leavell \& Clark e por Chaves;

- a assistência progressiva;

- 0 atendimento adequado e eficaz ao paciente, condizente com a filosofia e política das instituiçōes envolvidas (órgão formador e assistencial), e da enfermagem;

- a avaliação permanente e a autoavaliação do desempenho;

- a obtenção de melhor status social do aluno e da enfermagem como profissão;

- açōes sistematizadas que propiciem melhor caracterização do profissional.

\subsection{MARCOS FILOSÓFICOS}

A integração Docente-Assistencial tem como marcos filosóficos:

- estabelecer um relacionamento dinâmico entre professor-alunoequipe; aluno-paciente-famíliacomunidade;

- aproveitar ao máximo os recursos disponíveis para a oferta de uma assistência qualitativa e quantitativamente satisfatória, evitan- 
PIRES, L.S. e Colaboradoras - Importância da Integraçāo Docente-Assistencial - Uma Tentativa Realizada em um Hospital Militar - Rev. Bras. Enf.; DF, 35 : 95-101, 1982.

do, desta forma, a sub-utilização ou pulverização de recursos;

- a oferta de assistência adequada à saúde, fundamentada nos direitos humanos.

\section{ATIVIDADES DESENVOLVIDAS}

As atividades desenvolvidas no processo de integração Docente-Assistencial podem ser apresentadas sob dois enforgues:

\subsection{ESPECIFICAÇAO}

Agruparam-se as atividades, de acordo com a fase do processo, assim constituídas: fase introdutória, de integração e avaliação, melhores descritas e explicitadas no Modelo Operativo (Anexo I).

\subsection{MODELO OPERATIVO}

O Modelo Operativo, apesar de previamente estabelecido, é susceptível a mutaçōes, de acordo com as inovaçōes ou alterações pretendidas, criatividade, necessidades educacionais, institucionais e do cliente.

Compōe-se das fases e atividades:

1. ${ }^{a}$ fase - Introdutória, constituída de:

- convite do Diretor do hospital para a realização do ensino prático no hospital, tendo sido aceito pela direção do Departamento de Enfermagem;

- entrevista oficiosa com a direção do hospital e com a equipe multiprofissional, e em particular com a equipe de enfermagem, visando a colher algumas informaçōes úteis quanto ao campo para a prática dos acadêmicos de enfermagem;

- levantamento dos tipos de assistência prestada pelo hospital e recur- sos disponiveis, a fim de evitar possiveis intercorrências no ensino, possibilitando os reajustes cabiveis e tentando adaptar a realidade do ensino teórico à prática;

- previsão de material, para a provisão necessária, segundo a disponibilidade da instituição e, se necessário, auxiliando no provisionamento mínimo para a otimização da assistência;

- entrosamento oficial com a direçāo e equipe de enfermagem do hospital, no intuito de encontrar medidas conciliadoras entre Instituição Hospitalar-Departamento de Enfermagem da Universidade;

- reunião com o corpo docente, que prioritariamente pretendia utilizar as unidades de internação desse hospital como campo de ensino clinico, objetivando planejar as atividades discentes, em conformidade com a realidade prática:

- reunião com a equipe de enfermagem do Hospital, para ciência ao programa, solicitando sugestōes e recomendações.

$2 .^{\text {a }}$ fase - Integração, comportando as atividades:

- programação das atividades a serem desenvolvidas pelo alunado, incluindo os procedimentos, técnicas, princípios científicos, situaçōesproblema, estudo de casos, acompanhamento familiar, propósitos e metas;

- estabelecimento de critérios e metas para avaliação da evolução do aluno na prática desenvolvida;

- provisão do material necessário ao desempenho dos cuidados de enfermagem e técnicas básicas;

- designação de um Auxiliar de Ensino, para dedicar parte de seu horário à instituição, com o propósito de 
PIRES, L.S. e Colaboradoras - Importância da Integraçāo Docente-Assistencial - Uma Tentativa Realizada em um Hospital Militar - Rev. Bras. Enf.; DF, 35 : 95-101, 1982.

servir de elemento de ligação entre o corpo docente e discente e a equipe de saúde do hospital.

As açōes exercidas por esse elemento são somente didáticas, voltadas para aquelas eminentemente de apoio e incluem:

- receber e distribuir os alunos e professores pelas unidades de internação;

- colaborar no controle e distribuição de estágios;

- contactar com professores e equipe de enfermagem do hospital, para identificar os possiveis problemas existentes, os efeitos da permanência dos alunos na instituição e necessidades sentidas;

- receber e analisar diariamente os relatórios redigidos pelos alunos, quanto à prática desenvolvida $\mathrm{e}$ fatores impeditivos para exercêla;

- encaminhar os problemas e necessidades sentidas à direção do Departamento de Enfermagem. para, em conjunto com os professores, procurarem alternativas para solucioná-los, atendê-los, minimizá-los e preferentemente evitá-los;

- implantação de um sistema de Educação Continuada e de Treinamento em Serviço, visando despertar no pessoal de enfermagem do hospital o desejo de aquisição e renovação de conhecimentos científicos modernos e mais a participação no ensino prático;

- dinamização do Estágio Supervisionado na instituição hospitalar, objeto desta abordagem, a fim de permitir maior continuidade da assistência prestada pelos alunos e um relacionamento dinâmico entre alunos-pacientes e famílias e equipe multiprofissional;
- realização de estudos, para verificar cientificamente a aceitação dos alunos, resultados obtidos na assistência, aplicação de princípios científicos, status social na instituição e verificar os fatores impeditivos na prática de ensino e no êxito profissional.

O processo de integração está sendo paralelamente acompanhàdo pela 3 . $^{\mathrm{a}}$ fase, a seguir:

3. ${ }^{a}$ fase - Avaliação - de caráter educativo, dinâmico e progressivo, no intuito de obter-se a consecução dos objetivos estabelecidos nesta integração.

As atividades desenvolvidas nesta fase constituem:

- avaliação permanente do desempenho dos alunos e dos fatores interferentes nas açōes desempenhadas por eles;

- institucionalização de um sistema de auto-avaliação do professor, aluno e equipe;

- estabelecimento de um processo participativo e dinâmico de avaliação de todo o pessoal envolvido nesta integração, com ênfase no paciente;

- avaliação dos efeitos da prática oferecida pelos alunos à instituição.

A dinâmica funcional e administrativa das atividades Docentes-Assistenciais representa um ponto-chave nas assistência, pois permite medir-se o valor do indivíduo na instituição, tendo como parâmetro a capacidade de tornar as coisas melhores, tomar decisōes em tempo mais curto e com menor custo.

\section{CONCLUSÕES}

A Integração Docente-Assistencial constitui uma das estratégias que permitem a maior participação do órgão for- 
PIRES, L.S. e Colaboradoras - Importância da Integraçāo Docente-Assistencial - Uma Tentativa Realizada em um Hospital Militar — Rev. Bras. Enf.; DF, 35 : 95-101, 1982.

mador e do órgão assistencial no Sistema Nacional de Saúde, favorecendo a prática de assistência à saúde em consonância com a realidade brasileira.

Para tanto, torna-se necessário que seja elaborado um Modelo Operativo capaz de dirigir e avaliar as ações da equipe de enfermagem, em busca da otimização do processo: Ensino-Aprendizagem-Assistência.

Este Modelo Operativo deve ser funcional, com base nos propósitos da Educação, Assistência, necessidades da clientela, bem como na política filosófica e administrativa, tanto da enfermagem como profissão como do órgão Formador e Assistencial da área de saúde.

Esta Integração Docente-Assistencial independe do tipo de subordinação administrativa das instituições de Ensino e Assistencial, ou seja, pode estar diretamente ligada ao Modelo Operativo e à dinâmica adotada na implementação deste modelo.

\section{RECOMENDAÇŐES}

A experiência que está sendo vivida nesta tentativa de Integração DocenteAssistencial, tendo como órgãos envolvidos duas instituições de caráter especiais, propõe as seguintes recomendações:

- Experimentação do modelo adotado, visando a verificar-se a sua operacionalidade em outros órgãos similares ou mesmo da rede federal, estadual, municipal, autárquico ou particular.

- A realização de pesquisas cientificas capazes de estudar novos modelos.

- A adoção desta estratégia preconizada para uma oferta de assistência mais qualitativa e a obtenção de melhores resultados no ensino teórico e prático.

B I B L IOG R A F I A

1. DANTAS, I. P - A Enfermagem de Saúde Pública na Assistência Materno-Infantil. Editora JUERP. Rio de Janeiro, 1978.

2. KISIL, Marcos - $\mathrm{O}$ cuidado progressivo do paciente: uma experiência administrativa em centro médico complexo. Bol. Of. Sanit. Panam., 5(1), 1978.

3. PAIM, R. C. et alii - Implementaçāo do Núcleo de Orientação à Saúde para a clientela Materno Infantil numa Escola de Universidade particular - Uma tentativa de integração Docente-Assistencial XXXII Congresso Brasileiro de Enfermagem. Brasília, 1980

4. SAÚDE, Ministério da $-\mathrm{V}$ Conferência Nacional de Saúde. Brasília, 1975.

5. SOBREIRA, N. R. - Enfermagem Comunitária - no prelo. Rio de Janeiro, 1981 
PIRES, L.S. e Colaboradoras - Importância da Integração Docente-Assistencial - Uma Tentativa Realizada em um Hospital Militar - Rev. Bras. Enf.; DF, 35 : 95-101, 1982.

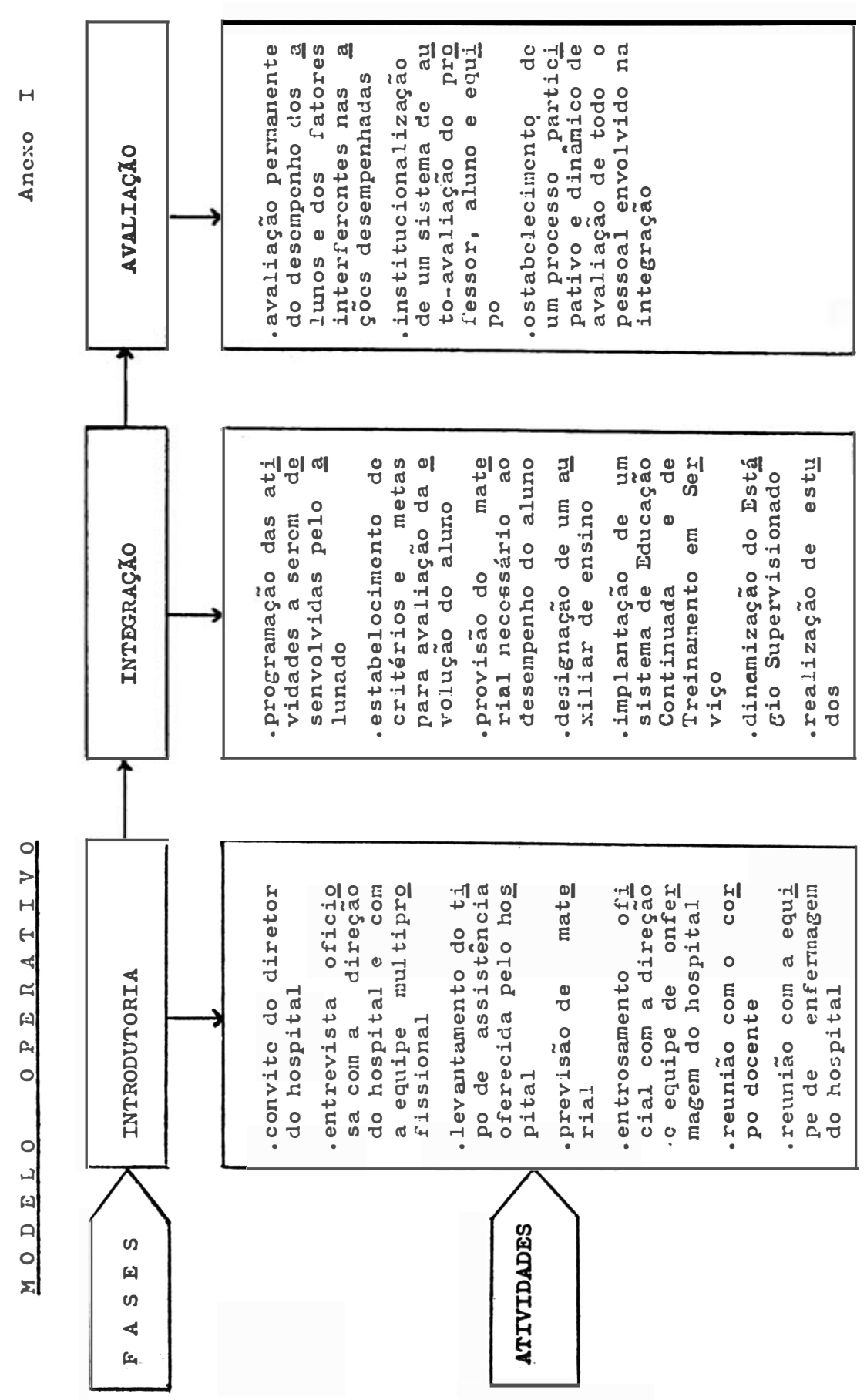

